\title{
A New Route of Synthesis and Characterization of Biocompatible Gold Nanoparticles from Synthetic Japanese Natural Medicine
}

\author{
Samir Kumar Mandal \\ Department of Chemistry, P. D. Women's College/ North Bengal University, Jalpaiguri, India- 735101
}

\begin{abstract}
Redox behavior of phenolic substrate is well established method for preparation of gold nanoparticles (GNPS) from gold salt. Natural medicine containing phenolic hydroxyl group was used as not only reducing agent but also as stabilizer. Newly synthesis of GNPs at ambient condition shows good stability over a period of time with mono-dispersed in nature. GNPs were characterized by ultraviolet visible spectroscopy, transmission electron microscopy, X-ray powder diffraction.
\end{abstract}

Keywords- ambient temperature, eco-friendly synthesis, gold nanoparticles, natural medicine, redox reaction.

\section{INTRODUCTION}

Usefulness of biomaterials and metal catalyst in many reactions is an urgent need of the society to fulfill our requirements. As per the environmental issue it is our responsibility to avoid hazardous effect of metal. So choice of biocompatible and micro- to nano-gram scale catalyst instead of toxic and gram scale is critical. Recent development of nanometer scaled metal particles have attracted significantly with new area of research - Nanomaterial Science and Technology [1,2]. They are widely precious in the field of chemical synthesis to biomedicine [3-6].

Gold nanoparticles (GNPs) have properties that are different from the bulk metals due to their small size. They are useful in catalysis, magnetism, single electron tunneling devices, DNA sequencing, biomolecular recognition and many others [7,8]. The discovery of gold nanoparticles (GNPs) as catalyst for the reduction of nitroaromatic compounds has established new possibilities for the production of aniline derivatives [9-12]. This help scientists to probe new possibility for planning efficient and clean synthetic routes for the preparation of polyfunctional nitrogenated compounds of highly demanded chemicals [13]. A very recent report shows chemoselective reduction of substituted nitroaromatic compounds for preparation of polyfunctional nitrogenated compounds by means of cascade reactions [14]. Mirkin and co-workers reported a new method for colorimetric detection of targeted DNA sequences based on gold colloidal particles size controlled by oligonucleotide linkers of varying length [15]. Thus growing interest of GNPs in the field of catalysis to bioanalytical field provides a progressive movement to the improvement of their novel preparation methods [16].

The conventional methods for preparation of GNPs describes reduction of tetrachloroauric acid $\left(\mathrm{HAuCl}_{4}\right)$ in aqueous medium. Most widely used reducing agents are sodium citrate, sodium borohydride, block copolymers or ascorbic acid [17]. In this process GNPs dispersed in solution due to ionic repulsion and absorbed on the surface and have the general tendency to aggregate due to shielding of charge. So choice of stabilizer is crucial to prevent aggregation which is soluble in the medium. Many have used water-soluble polymers such as starches, PEG, SDS, amine etc [18]. Organic metal nanocomposites have diverse advantages which lead the scientists to find out the proper materials [19]. Water-dispersible GNPs have been synthesized by redox technique at room temperature using poly(4-vinylphenol) $(\mathrm{PVPh})$ as a simultaneous template, stabilizer and reducing agent [20]. Still alternative method is require for sensitive use of biomedicine as $P E G$ compounds themselves show some evidence of genotoxicity [21]. Thus the hot spot of current research in nanomaterial science and technology is the synthesis of GNPs from biomaterial using plants or plant extracts [22,23], fungus [24-26], and bacteria [27,28]. Very recently synthesis of GNPs using chloroplasts as reductants and stabilizers have been reported and showed great potential for ultrasensitive detection of biomarkers in vitro and in vivo based on surface-enhanced Raman spectroscopy (SERS) [29]. Most of the method needs the complex biological components and costly biological resources.

Chemically synthesized bioactive compound may be excellent alternative methods for synthesis of GNPs. This encouraged the current author to use chemically synthesized natural medicine such as $( \pm)$ hydrangenol and ( \pm )-thunberginol-G as the potential biological template for preparation of GNPs. The hypothesis of the present work is based on the utilization of redox active phenolic hydroxyl group of the chemically synthesized natural compound as the potential source for reduction of gold salts into their corresponding nanoparticles. Although expected, author was fortunate enough that the template act as simultaneous stabilizer and reducing agent. Present work reports that ( \pm )-hydrangenol and $( \pm)$-thunberginol-G are capable to reduce gold ion under aqueous condition in ethanol-water media to yield highly stable gold nanoparticle. 


\subsection{Preparation of the template}

\section{EXPERIMENTAL}

Initially the chemical synthesis was carried out from commercially available 2-methyl-6-nitrobenzoic acid. This was converted to the radical precursor for Barbier type of reaction followed by radical addition to the suitably substituted aldehyde to result ( \pm )-hydrangenol and ( \pm )-thunberginol-G (Scheme 1) as depicted earlier by the same author [30].

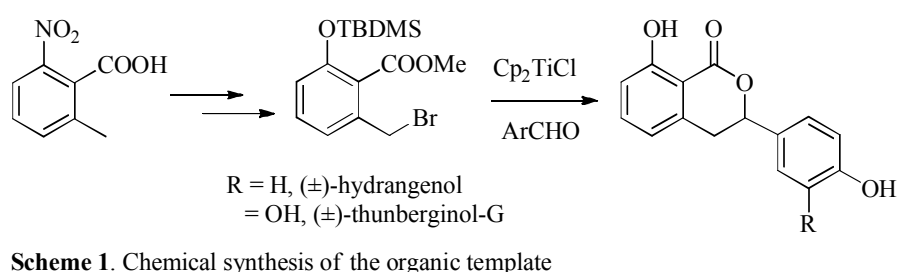

\subsection{Synthesis of GNPs [31-33]}

\subsubsection{Method A}

To a stirred solution of $2.5 \mathrm{~mL} 1 \mathrm{mM}$ ethanolic solution of ( \pm )-hydrangenol $0.1 \mathrm{~mL}$ of $0.1 \mathrm{M} \mathrm{KOH}$ solution was added. After dissolution, $1.0 \mathrm{~mL}$ of $1 \mathrm{mM} \mathrm{HAuCl}_{4}$ was added slowly to provide homogeneity at room temperature. The yellow color slowly changed to violet color within $6 \mathrm{~h}$ indicates the formation of gold nanoparticle.

\subsubsection{Method B}

To a stirred solution of $5 \mathrm{~mL} 1 \mathrm{mM}$ ethanolic solution of ( \pm )-hydrangenol or ( \pm )-thunberginol-G $2.0 \mathrm{~mL}$ of $1 \mathrm{mM} \mathrm{HAuCl}{ }_{4}$ was added slowly to provide homogeneity at room temperature. The yellow color slowly changed to violet color within $2 \mathrm{~h}$ for ( \pm )-hydrangenol and within a minute for ( \pm )-thunberginol-G indicates the formation of gold nanoparticle.

\subsection{Chemicals}

Aqueous $1 \% \mathrm{HAuCl}_{4} \cdot 3 \mathrm{H}_{2} \mathrm{O}$ solution (Sigma, $>49 \%$ as gold) and Millipore Milli-Q system (18 $\mathrm{m} \Omega$ ) were used for the preparation of colloidal gold. Anhydrous ethanol was purchased from Aldrich chemical company.

\subsection{Spectral data of ( \pm )-hydrangenol and ( \pm )-thunberginol-G [30]}

2.4.1. ( \pm )-hydrangenol: IR (KBr) 3354, 1658, 1460, 1230, $1028 \mathrm{~cm}^{-1}$; ${ }^{1} \mathrm{H}$ NMR (300 MHz, $\mathrm{d}_{6}$-DMSO): $\delta 3.10$ $(\mathrm{dd}, J=2.5,16.4 \mathrm{~Hz}, 1 \mathrm{H}), 3.37(\mathrm{dd}, J=12.0,16.4 \mathrm{~Hz}, 1 \mathrm{H}), 5.63(\mathrm{dd}, J=2.5,12.0 \mathrm{~Hz}, 1 \mathrm{H}), 6.79(\mathrm{~d}, J=8.2 \mathrm{~Hz}$, 2H), $6.83-6.89(\mathrm{~m}, 2 \mathrm{H}), 7.31(\mathrm{~d}, J=8.2 \mathrm{~Hz}, 2 \mathrm{H}), 7.50(\mathrm{t}, J=7.9 \mathrm{~Hz}, 1 \mathrm{H}), 9.62(\mathrm{~s}, 1 \mathrm{H}$, Phenolic OH), $10.92(\mathrm{~s}$, $1 \mathrm{H}$, Phenolic OH); ${ }^{13} \mathrm{C}$ NMR (75 MHz, $\mathrm{d}_{6}$-DMSO): $\delta 34.4,81.4,109.3,116.1(2 \mathrm{C}), 116.3,119.1(2 \mathrm{C}), 129.2$, 129.3, 137.2, 141.5, 158.7, 161.8, 170.2; HRMS calcd for $\mathrm{C}_{15} \mathrm{H}_{12} \mathrm{O}_{4} \mathrm{Na}[\mathrm{M}+\mathrm{Na}]^{+} 279.0633$, found 279.0649.

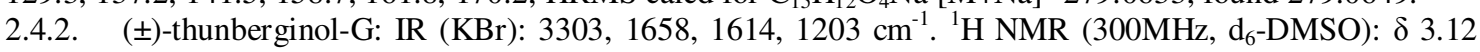
$(\mathrm{dd}, J=2.9,16.5 \mathrm{~Hz}, 1 \mathrm{H}), 3.33(\mathrm{dd}, J=11.8,16.5 \mathrm{~Hz}, 1 \mathrm{H}), 5.59(\mathrm{dd}, J=2.9,11.8 \mathrm{~Hz}, 1 \mathrm{H}), 6.77-6.91(\mathrm{~m}, 5 \mathrm{H})$, $7.51(\mathrm{dd}, J=7.8,7.9 \mathrm{~Hz}, 1 \mathrm{H}), 9.07(\mathrm{~s}, 1 \mathrm{H}), 9.10(\mathrm{~s}, 1 \mathrm{H}), 10.95$ (s, $1 \mathrm{H}) .{ }^{13} \mathrm{C}$ NMR $\left(75 \mathrm{MHz}, \mathrm{d}_{6}-\mathrm{DMSO}\right): \delta 33.1$, 80.0, 108.0, 113.7, 114.9 (2C), 117.3, 117.9, 128.5, 135.8, 140.1, 144.7, 145.3, 160.4, 168.9. HRMS calcd. for $\mathrm{C}_{15} \mathrm{H}_{12} \mathrm{O}_{5} \mathrm{Na}[\mathrm{M}+\mathrm{Na}]^{+} 295.0583$, found 295.0584.

\subsection{UV-Vis spectroscopy}

UV-Vis spectroscopy was utilized to measure the presence of a Surface Plasmon Resonance (SPR) peak using U-2800 Spectrophotometer. UV-Vis spectroscopic measurements were operated at a resolution of 1 $\mathrm{nm}$ at a range of 200-800 $\mathrm{nm}$ with a scanning speed of $400 \mathrm{~nm} / \mathrm{min}$. The presence of surface plasmon band around $545 \mathrm{~nm}$ observed in UV-visible spectrum indicates the formation of gold nanoparticle.

\subsection{Transmission electron microscopy measurements and $\mathrm{X}$-ray diffraction analysis}

The diameter of the GNPs was determined by transmission electron microscopy (TEM) on JEOL JEM2010 electron microscope using a $200 \mathrm{kV}$ accelerating voltage. Sample of HRTEM were prepared by placing a drop of gold suspension on a clear, dry 300 mesh copper grid coated with carbon film and allowed to dry for few hour. The typical HR-TEM image of GNPs had clear lattice fringes. The X-ray diffraction pattern (XRD) of GNPs was confirmed by using the Rich-Seifert XRD 3000P. The scanning was done in the region of the $2 \theta$ angle from $20^{\circ}$ to $80^{\circ}$. Typical X-ray diffraction pattern of the sample deposited on glass surface is in good agreement of the cubic phase gold nanocrystal. The diffraction peaks, which appeared at $38.2^{\circ}, 44.4^{\circ}$, 
$64.8^{\circ}$, and $78.8^{\circ}$, were recognized to the (111), (200), (220), and (311) planes, respectively. The distinctive selected areas electron diffraction (SAED) pattern with bright circular rings suggested that the GNPs were highly crystalline.

\section{RESULTS AND DISCUSSION}

A solution of compound in ethanol was prepared and $\mathrm{KOH}$ was added with stirring. Addition of yellow solution of gold-salt changes the color slowly which suggested the formation of GNPs. UV-Vis spectra of GNPs displayed surface plasmon resonance (SPR) band at about $547 \mathrm{~nm}$ (Fig. A) for ( \pm )-hydrangenol according to the method A but a sharp peak was obtained for ( \pm )-thunberginol-G without use of KOH solution (Fig. B) according to the method B. Bragg reflections of fcc gold (Fig. 1) are thus in agreement with the electron diffraction results (Fig. 2).

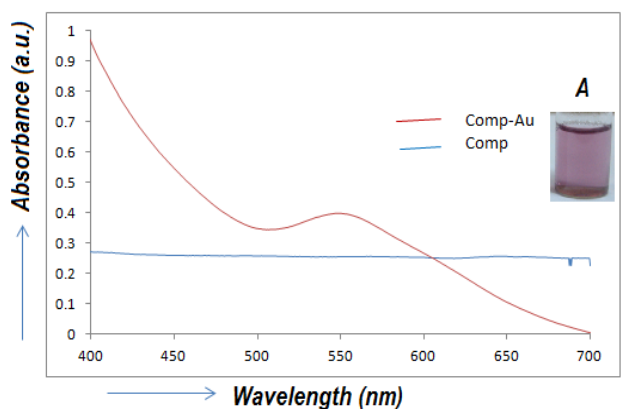

UV-visible absorption spectra of as-prepared gold nanoparticles. Inset photograph shows the reaction solution.

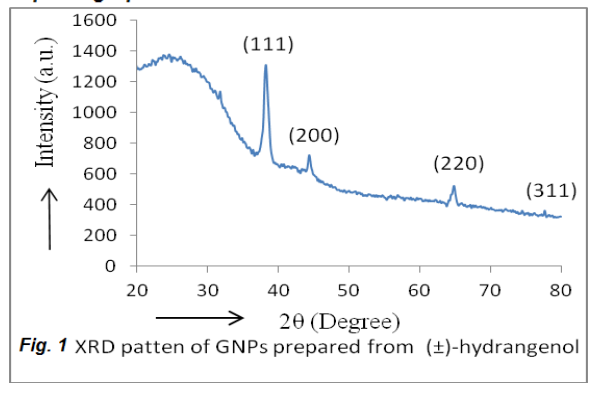

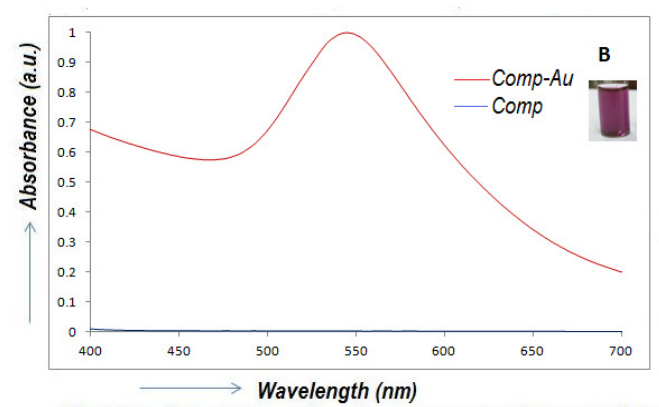

UV-visible absorption spectra of as-prepared gold nanoparticles. Inset photograph shows the reaction solution.

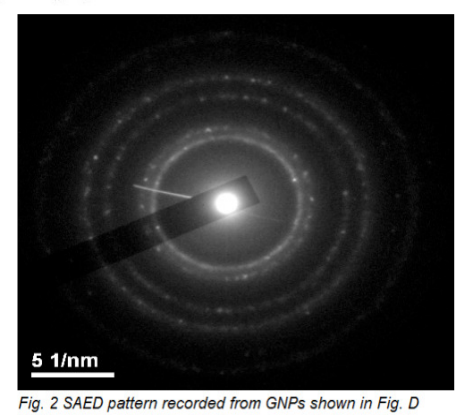

For ( \pm )-hydrangenol the intensity of the SPR band does not increase to an expected extent but remains broad over time which means there may be an aggregation of the particles with distribution of broad rang particles size. The color of the reaction solution was bluish pink (Fig. C, a). This is a good agreement of polydispersed GNPs as observed by TEM image (Fig. D). So, it was considered by checking the stability of the GNPs by altering the using and not using of base which support the formation of GNPs rapidly including the solubility of the template. A comparison using with and without $\mathrm{KOH}$ solution showed that sharp SPR band was obtained without $\mathrm{KOH}$ solution from the pink color GNPs solution (Fig. E, a) of ( \pm )-thunberginol-G. At high magnification, monodispersed GNPs was observed by TEM image (Fig. F) but in low magnification it shows like a bunch of grapes (Fig. G).

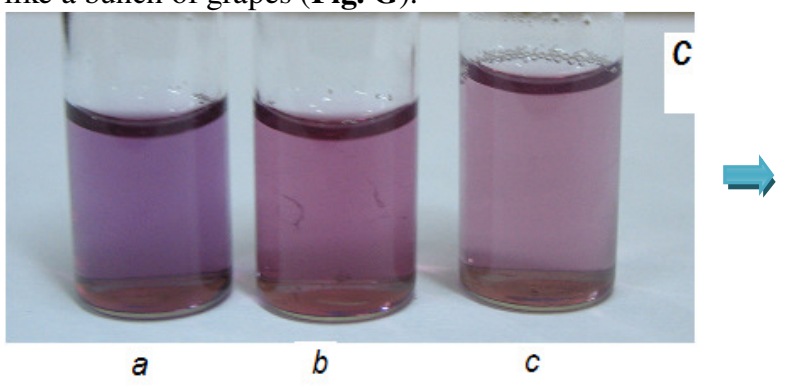

a. With $\mathrm{KOH}( \pm)$-hydrangenol in ethanol

b. without $\mathrm{KOH}( \pm)$-thunberginol-G in ethanol

c. Without $\mathrm{KOH}( \pm)$-hydrangenol in ethanol

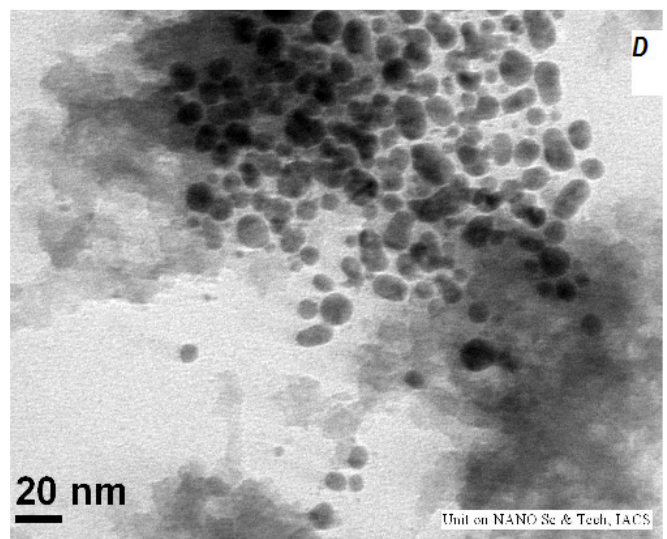




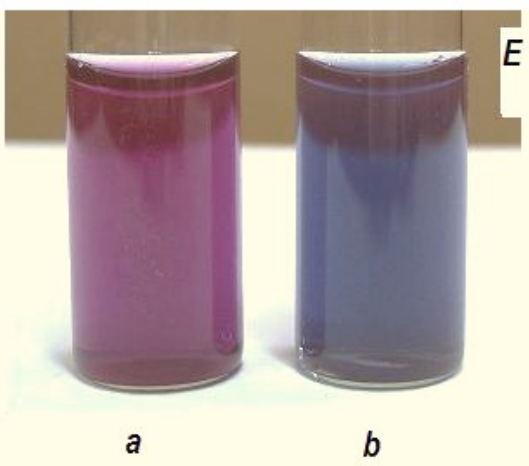

a. Without $\mathrm{KOH}( \pm)$-thunberginol-G in ethanol b. Without $\mathrm{KOH}( \pm)$-thunberginol-G in water

Solutions of GNPs synthesized/stabilized by $( \pm)-$ hydrangenol or ( \pm )-thunberginol-G (Fig. C and E)

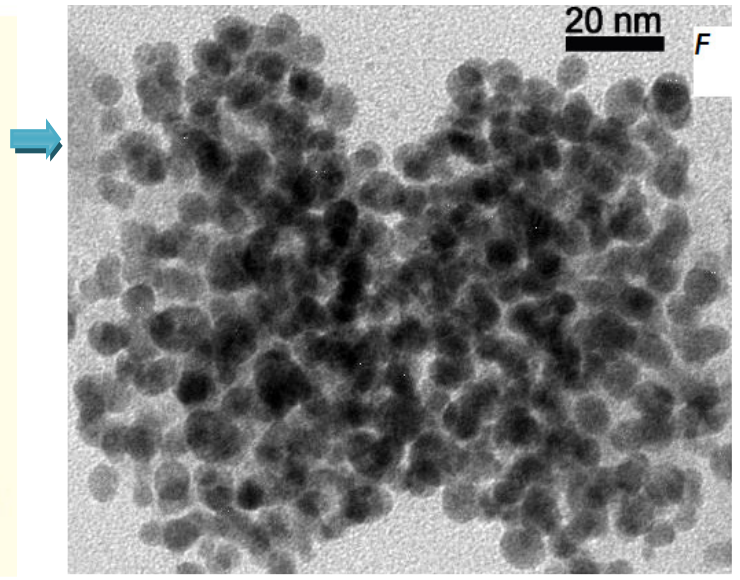

GNPs synthesized/stabilized by $( \pm)$-hydrangenol

(Fig. D) and ( \pm )-thunberginol-G (Fig. F)

UV-vis spectra show a shift of $\lambda_{\max }$ value from $548 \mathrm{~nm}$ to $535 \mathrm{~nm}$ within 50 minutes (Fig. 3\&4) with increasing intensity of absorbance. This solution remains stable for a period of month as no change in $\lambda_{\max }$ value was observed. TEM image (Fig. H\&I) of well separated GNPs was taken from low dense area which show average particle size is around 9-10 nm (Fig. 5). However the use of water as only solvent shows the opposite trend in UV-vis spectra (Fig. 6\&7) that is a shift of $\lambda_{\max }$ value towards higher wavelength with broadening. The intensity gradually falls with longer time and the SPR band becomes broad which suggests aggregation of the metal particles. Polydispersed GNPs was observed by TEM image (Fig. J) suggesting the distribution in good agreement with the spectra. So, use of ethanol is crucial to prevent the aggregation of GNPs (Fig. E). It is expected as the template is partially water soluble. This aggregation is also a common when it is carried out beyond the room temperature. Biomolecules on the surface of GNPs cannot be observed under TEM image but visible in FE-SEM. This data was recorded after a month of preparation of the solution of Fig. A just to know the morphology of the template and the particles (Fig. K).
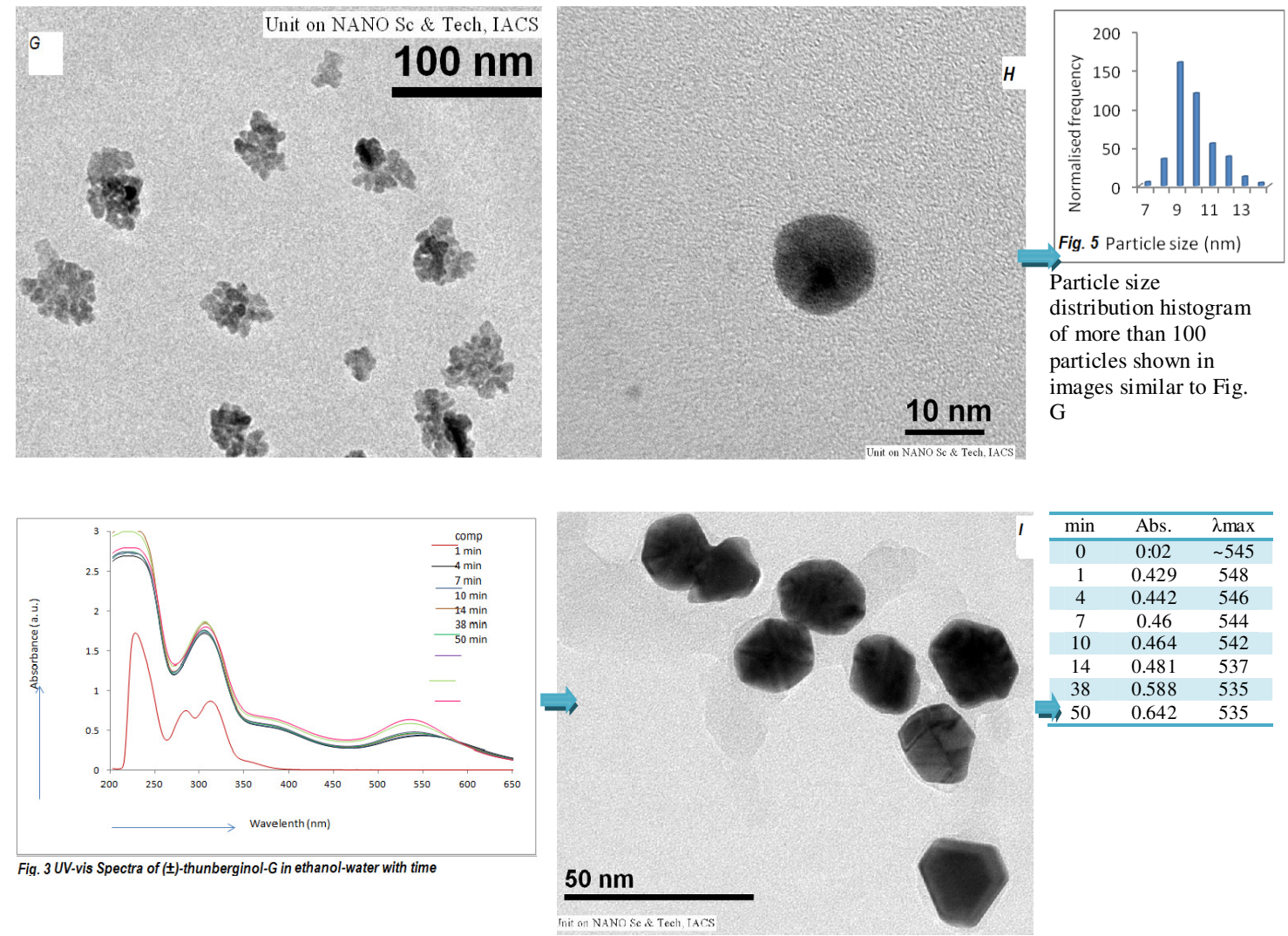

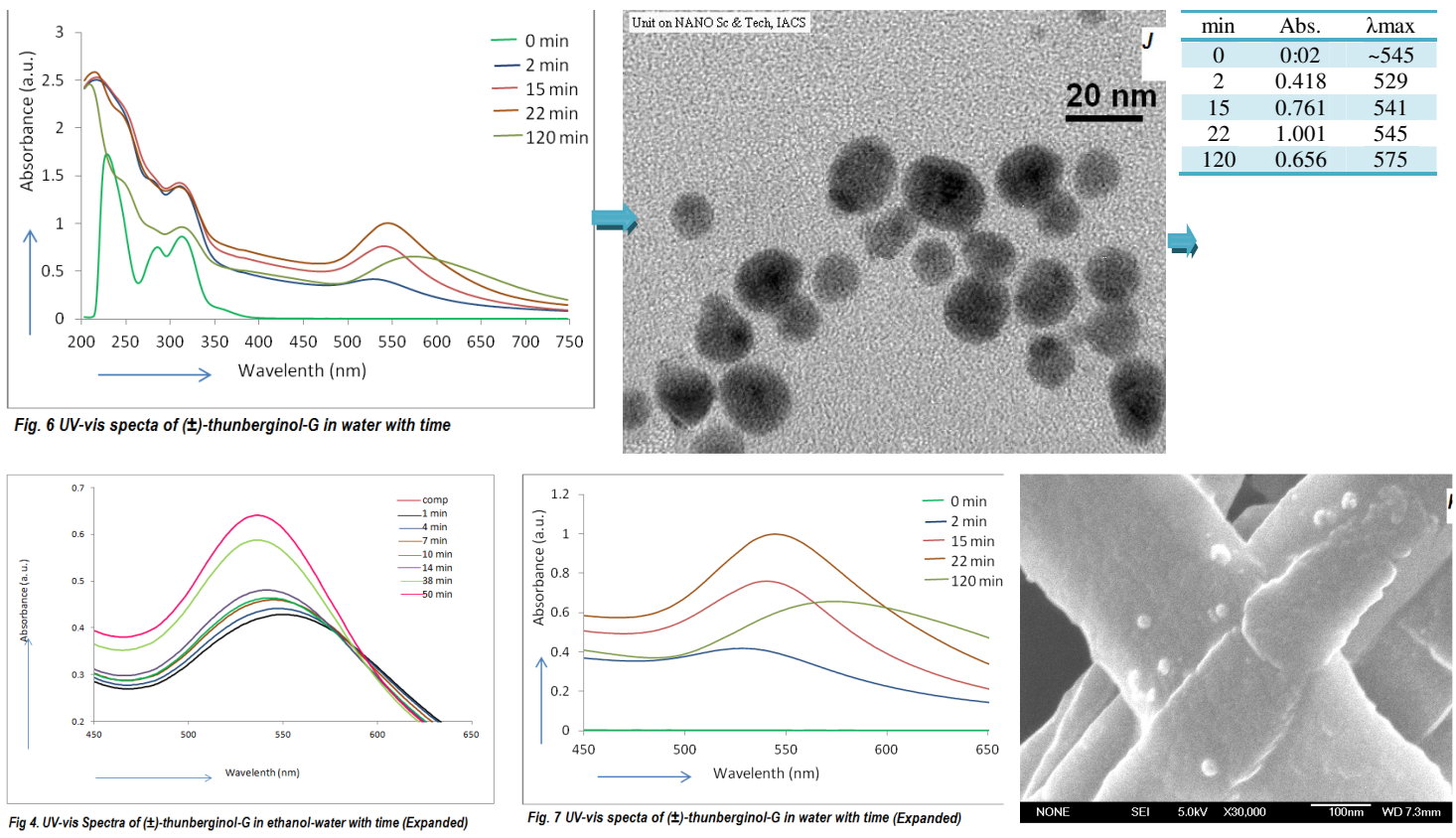

Fig. 3, 4, 5, 6 represents UV-Vis spectra of GNPs synthesized/stabilized by ( \pm )-thunberginol-G

Fig. G, H, I, J represents GNPs synthesized/stabilized by ( \pm )-thunberginol-G.

\section{CONCLUSION}

In conclusion, author is successful to report that ( \pm )-hydrangenol and ( \pm )-thunberginol-G are capable to reduce gold ion to yield highly stable gold nanoparticle even after several days under aqueous condition in ethanol-water media and don't show any particles growth or loss of solubility in room temperature. It is expected that the newly developed method may bring opportunity to be useful in the field of biomedicine, biomarker, biosensor, bioseparations, bioimaging, biotherapy including catalysts, optical probes. At present due to limitation of the infrastructure it is unfortunate to show significant application in the above mentioned field but surely there is a scope in near future and will be published elsewhere.

\section{Acknowledgements}

Author acknowledges CSS of IACS, Jadavpur for giving the opportunity to record spectral data and wants to thank Prof. S. C. Roy, IACS, Jadavpur, Prof. A. K. Das, IIT, Indore and Dr. R. N. Mitra for helping in several occasions.

\section{REFERENCES}

[1] K. Watanabe, D. Menzel, N. Nilius, H.-J. Freund, Photochemistry on metal nanoparticles, Chem. Rev., 106(10), 2006, 4301-4320.

[2] J. Dobson, Magnetic micro- and nano-particle-based targeting for drug and gene delivery, Nanomedicine, 1(1), 2006, 31-37.

[3] I. S. Lee, N. Lee, J. Park, B. H. Kim, Y.-W. Yi, T. Kim, T. K. Kim, I. H. Lee, S. R. Paik, T. Hyeon, Ni/NiO core/shell nanoparticles for selective binding and magnetic separation of histidine-tagged proteins, J. Am. Chem. Soc., 128(33), 2006, 10658-10659.

[4] S. Kim, H. Huang, H. E. Pudavar, Y. Cui and P. N. Prasad, Intraparticle energy transfer and fluorescence photoconversion in nanoparticles: an optical highlighter nanoprobe for two-photon bioimaging, Chem. Mater., 19(23), 2007, 5650- 5656.

[5] P. B. Monaghan, K. M. McCarney, A. Ricketts, R. E. Littleford, F. Docherty, W. E. Smith, D. Graham and J. M. Cooper, BeadBased DNA Diagnostic Assay for Chlamydia Using Nanoparticle-Mediated Surface-Enhanced Resonance Raman Scattering Detection within a Lab-on-a-Chip Format, Anal. Chem., 79(7), 2007, 2844-2849.

[6] X. Huang, P. K. Jain, I. H. El-Sayed and M. A. El-Sayed, Gold nanoparticles: interesting optical properties and recent applications in cancer diagnostics and therapy, Nanomedicine, 2(5), 2007, 681-693.

[7] J. H. Fendler, Nanoparticles and Nanostructured Film: Preperation, Characterization and Application; Wiley-VCH: Weinhein, 1998.

[8] A. Stephen K. Hashmi, Gold-catalyzed organic reactions, Chem. Rev., 107(7), 2007, 3180-3211.

[9] A. Corma and P. Serna, Chemoselective hydrogenation of nitro compounds with supported gold catalysts, Science, 313(5785), 2006, $332-334$.

[10] A. Grirrane, A. Corma and H. Garcia, Gold-catalyzed synthesis of aromatic azo-compounds from anilines and nitroaromatics, Science, 322(5908), 2008, 1661-1664.

[11] A. Corma, P. Concepción and P. Serna, A different reaction pathway for the reduction of aromatic nitro compounds on gold catalysts, Angew. Chem. Int. Ed., 46(38), 2007, 7266-7269.

[12] M. Boronat, P. Concepción, A. Corma, S. González, F. Illas and P.Serna, A molecular mechanism for the chemoselective hydrogenation of substituted nitroaromatics with nanoparticles of gold on tio2 catalysts: a cooperative effect between gold and the support, J. Am. Chem. Soc., 129(51), 2007, 16230-16237.

[13] L. F. Tietze, Domino Reactions in Organic Synthesis, Chem. Rev., 96(1), 1996, 115-136. 
[14] Laura L. Santos, Pedro Serna, and A. Corma, Chemoselective synthesis of substituted imines, secondary amines, and $\beta$-amino carbonyl compounds from nitroaromatics through cascade reactions on gold catalysts, Chem. Eur. J., 15(23), $2009,8196-8203$.

[15] J. J. Storhoff, A. A. Lazarides, R. C. Mucic, C. A. Mirkin, R. L. Letsinger and G. C. Schatz, What controls the optical properties of dna-linked gold nanoparticle assemblies? J. Am. Chem. Soc., 122(19), 2000, 4640- 4650.

[16] K. R. Brown, D. G. Walter and M. J. Natan, Seeding of Colloidal Au Nanoparticle Solutions. 2. Improved Control of Particle Size and Shape, Chem. Mater., 12(2), 2000, 306-313.

[17] M. Murawska, A. Skrzypczak, M. Kozak, Structure and morphology of gold nanoparticles in solution studied by TEM, SAXS and U-Vis, Acta Phys. Pol.A 121(4), 2012, 888-892.

[18] L. M. Bronstein, S. N. Gourkova, A. Y. Sidorov, P. M. Valetsky, J. Hartmann, M. Breulmann, H. Colfen and M. Antonietti, Interaction of metal compounds with 'double-hydrophilic' block copolymers in aqueous medium and metal colloid formation, Inorg. Chim. Acta, 280, 1998, 348-354.

[19] R. J, Tseng, J. Huang, J. Ouyang, R. B. Kaner and Y. Yang, Polyaniline nanofiber/gold nanoparticle nonvolatile memory. Nano Lett. 5(6), 2005, 1077-1080.

[20] R. R. Bhattacharjee, M. Chakraborty and T. K. Mandal, Synthesis of size-tunable gold nanoparticles by poly(vinylphenol) and electrostatic multilayer deposition of the gold-poly(vinylphenol) nanocomposites, J. Nanosci Nanotechnol., 4(7), $2004,844-848$.

[21] Wangenheim J and Bolcsfoldi G., Mouse lymphoma L5178Y thymidine kinase locus assay of 50 compounds, Mutagenesis, 3(3), 1988, 193-205.

[22] V. Kumar and S. K. Yadav, Plant-mediated synthesis of silver and gold nanoparticles and their applications, J. Chem. Technol. Biot., 84(2), 2009, 151-157.

[23] P. Rajasekharreddy, P. Usha Rani, B. Sreedhar, Qualitative assessment of silver and gold nanoparticle synthesis in various plants: a photobiological approach, J. Nanopart Res., 12(5), 2010, 1711-1721.

[24] J. Xie, J. Y. Lee, D. I. C. Wang, Y. P. Ting, High-yield synthesis of complex gold nanostructures in a fungal system. J. Phys. Chem. C., 111(45), 2007, 16858-16865.

[25] S. S. Shankar, A. Ahmad, R. Pasricha, M. Sastry, Bioreduction of chloroaurate ions by geranium leaves and its endophytic fungus yields gold nanoparticles of different shapes, J. Mater. Chem., 13(7), 2003, 1822-1826.

[26] P. Mukherjee, S. Senapati, D. Mandal, Extracellular synthesis of gold nanoparticles by the fungus Fusarium oxysporum, Chem. Bio. Chem., 3(5), 2002, 461-463.

[27] S. He, Y. Zhang, Z. Guo, N. Gu, Biological synthesis of gold nanowires using extract of Rhodopseudomonas capsulate, Biotechnol. Prog., 24(2), 2008, 476-480.

[28] Y. Feng, Y. Yu, Y. Wang, X. Lin, Biosorption and bioreduction of trivalent aurum by photosynthetic bacteria Rhodobacter capsulatus, Curr. Microbiol., 55(5), 2007, 402-408.

[29] Y. X. Zhang, J. Zheng, G. Gao, Y. F. Kong, X. Zhi, K. Wang, X. Q. Zhang and D X. Cui, Biosynthesis of gold nanoparticles using chloroplasts, Int. J. Nanomedicine, 6, 2011, 2899-2906.

[30] S. K. Mandal and S. C. Roy, Titanocene(III) chloride mediated radical-induced synthesis of 3,4-dihydroisocoumarins: synthesis of ( \pm )-hydrangenol, $( \pm)$-phyllodulcin, $( \pm$ )-macrophyllol and ( \pm )-thunberginol G, Tetrahedron, 64(49), 2008, $11050-11057$.

[31] A. Verma and V. M. Rotello, Surface recognition of biomacromolecules using nanoparticle receptors, Chem. Commun., (3), 2005, 303-312.

[32] S. Ray, A. K. Das and A. Banerjee, Smart oligopeptide gels: in situ formation and stabilization of gold and silver nanoparticles within supramolecular organogel networks, Chem. Commun., (26), 2006, 2816-2818.

[33] A. Swami, A. Kumar, M. D'Costa, R. Pasricha and M. Sastry, Variation in morphology of gold nanoparticles synthesized by the spontaneous reduction of aqueous chloroaurate ions by alkylated tyrosine at a liquid-liquid and air-water interface, J. Mater.Chem., 2004, 14(17), 2696-2702. 